\title{
Toric phakic IOLs in keratoconus-evaluation of preoperative parameters on the outcome of phakic anterior chamber lens implantation in patients with keratoconus
}

\author{
Isaak R. Fischinger ${ }^{1,2}$ (D) Jascha Wendelstein ${ }^{2} \cdot$ Kristin Tetz $^{1} \cdot$ Matthias Bolz $^{2} \cdot$ Manfred R. Tetz $^{1}$
}

Received: 3 November 2020 / Revised: 1 December 2020 / Accepted: 4 December 2020 / Published online: 19 January 2021

(C) The Author(s) 2021

\begin{abstract}
Purpose To evaluate the influence of the type of the keratectasia and preoperative keratometry readings on the efficacy of implantation of iris-fixated phakic anterior chamber intraocular lenses (pIOL) in patients with keratoconus.

Methods In this retrospective study, iris-fixated pIOLs (Artisan/Artiflex (Ophtec®), Verisyse/Veriflex (AMO®)) were implanted in 38 eyes of 22 patients with stable keratoconus. Thirty-six eyes underwent corneal crosslinking (CXL) prior to the lens implantation. The refractive outcome was evaluated 6 weeks postoperatively and the influence of preoperative refraction and topo- and tomographical factors were analyzed.

Results The mean postoperative uncorrected distance visual acuity (UDVA ${ }_{\text {post}}$ ) was $0.25 \pm 0.15 \operatorname{logMAR}$ and was not statistically different from the mean preoperative corrected distance visual acuity $\left(\mathrm{CDVA}_{\text {pre}}\right)$, which was $0.24 \pm 0.13 \operatorname{logMAR}$. Twenty-seven eyes $(71 \%)$ reached $\mathrm{UDVA}_{\text {post }} / \mathrm{CDVA}_{\text {pre }} \geq 1$ (efficacy index), whereas patients with PMD-like ectasia $(n=14)$ showed significantly $(p=$ $0.003)$ higher efficacy index $(100 \%)$ than patients diagnosed with keratoconus $(n=24)(54 \%)$. Higher eccentricity of the maximum posterior elevation showed a significant beneficial influence on the efficacy index $(p=0.021)$. Furthermore, a higher Amsler-Krumeich stage and preoperative MAE were correlated with a worse UDVA $_{\text {post. }}$ The mean absolute spherical equivalent was significantly decreased from $5.71 \pm 4.96 \mathrm{D}$ to $1.25 \pm 1.20 \mathrm{D}(p<0.001)$. No significant difference was found in endothelial cell count.

Conclusion The results indicate that the implantation of phakic iris-fixated anterior chamber IOLs is a reasonable refractive option for patients with keratoconus. Keratoconus patients with a pellucidal marginal degeneration (PMD)-like appearance ectasia seem to benefit most from such procedures.
\end{abstract}

Key Messages:

- Patients with corneal ectasia suffer from a poor uncorrected visual acuity and improvement can be challenging especially in patients with contact lens intolerance.

- Phakic iris-fixated anterior chamber lenses offer a feasible refractive treatment for stabilized keratoconus.

- Patients with lower preoperative astigmatism and pellucidal marginal degeneration (PMD)-like appearance of the keratoconus seem to benefit most from a phakic IOL implantation.

Keywords Keratoconus · Phakic-IOL · Pellucidal marginal degeneration · Corneal crosslinking

Isaak R. Fischinger

isaak.fischinger@hotmail.com

1 Department of Ophthalmology, Augentagesklinik Spreebogen Berlin, Alt-Moabit 101, 10557 Berlin, Germany

2 Department for Ophthalmology and Optometry, Kepler University Hospital GmbH, Johannes Kepler University Linz, Linz, Austria

\section{Introduction}

Keratoconus is a progressive disease with architectural alterations in the cornea, such as thinning and irregular bulging forward, which results of changes in the cornea's biomechanical properties $[1,2]$. From a refractive perspective, keratoconus 
can be characterized by astigmatism and higher-order aberrations such as coma and others. Pellucid marginal degeneration (PMD) is a much rarer disease, which is characterized by a more inferior peripheral thinning that results in a protrusion above the thinning and a crab-claw pattern on the topography map $[3,4]$. The predominant optical error is astigmatism with less higher-order aberrations than keratoconus. Differentiating between keratoconus and PMD from the refractive properties can be difficult as the transition of aberrations seems smooth; therefore, terms as PMD-like ectasia or inferior keratoconus arose to describe those hybrid types $[3,5,6]$. Visual rehabilitation by contact lenses or spectacles is challenging in both types of keratectasia since they are associated with a variety of refractive errors due to the irregular topography [7]. Prior to the introduction of corneal crosslinking (CXL) by Seiler et al. in 1996, the only available treatment in the course of these progressive diseases was a penetrating keratoplasty with higher risks of loss of visual acuity or severe complications [8]. Since the progression of keratectasias can now be stopped in most cases, the demand of a reasonable refractive treatment for the increasing population of patients with stable keratectasia is substantial, in particular, if contact lens intolerance is present. Corneal refractive procedures are removing tissue and consecutively inducing a further weakening of the cornea and should therefore be avoided in these cases $[9,10]$. Recently, an alternative approach is the use of phakic IOLs as a refractive treatment for stable keratectasia came up, however, these lenses were originally only designed for the treatment of regular astigmatism [11].

The previously published results of small sample size studies showed the potential of pIOLs to improve uncorrected visual acuity of patients with keratectasia. However, none of them assessed the influence of the type and level of keratectasia on the refractive success [12-15].

The aim of this retrospective study is to evaluate the influence of the type and stage of the keratectasia and keratometry readings on the refractive outcome after implantation of pIOLs.

\section{Patients and methods}

This retrospective study includes a total of 38 eyes of 22 patients suffering from stable keratectasia, all receiving irisfixated pIOLs between 2011 and 2018 in our clinic. The study protocol was approved by the ethical board of the institution and the local ethics committee (Berliner Ärztekammer, Eth36/19) and was conducted according to the principles of the Declaration of Helsinki. The entire study data was collected from the data of the Augentagesklinik Spreebogen Berlin.
The inclusion criteria were stable keratoconus, absence of earlier refractive treatment, clear cornea, minimum anterior chamber depth, and age-dependent endothelial cell count as recommended by the manufacturer, age over 18 , and welldocumented data of visual acuity. All patients gave written informed consent after being provided a detailed description of the nature of the treatment.

Thirty-six of 38 eyes underwent corneal crosslinking using the classical Dresden protocol with $3 \mathrm{~mW} / \mathrm{cm}^{2}$ in the past to halt progression of the corneal ectasia. The interval between the two procedures was 12 months in average.

The grading of the keratectasia and the differentiation between the subgroups was based on tomography imaging. The staging was done following the classical Amsler-Krumeich grading system $[16,17]$. To differentiate between keratoconus and PMD-like ectasia, the eccentricity of the maximum posterior elevation and pachymetry as well as the topographical appearance were evaluated (Fig. 1). An eccentricity of the maximum posterior elevation of less than $1.5 \mathrm{~mm}$ suggested a keratoconus, 1.5-2.8 $\mathrm{mm}$ a PMD-like ectasia and $>2.8 \mathrm{~mm}$ a PMD [5].

\section{Preoperative and postoperative measurements}

Preoperative measurements included manifest refraction, corrected distance visual acuity (CDVA), slit-lamp examination, dilated fundoscopy, pupillometry, tonometry, endothelial cell count, anterior chamber depth, and corneal tomography using HR Pentacam ${ }^{\circledR}$ (Oculus ${ }^{\circledR}$, Wetzlar, Germany). Postoperative follow-up visits were conducted 1 day, 1 week, and 6 weeks postoperatively. Preoperative data was compared with the data collected 6 weeks postoperatively.

\section{Phakic intraocular lenses}

Artisan (Ophtec $\AA)$, Artiflex (Ophtec $\AA)$, Verisyse (AMO®), and Veriflex $(\mathrm{AMO} 囚)$ lenses were implanted without brand preference depending on availability. Determination of the use of the rigid or flexible lens variants was based on the degree of myopia and astigmatism, as flexible lenses such as Artiflex and Veriflex are only available for a smaller range. The lens power was calculated by the manufacturer using the manifest refraction that rendered best visual acuity, $K$ values, and anterior chamber depth.

\section{Surgical procedure}

All treatments were performed by a single experienced surgeon (M.T.). The patient was prepared for the procedure with a peribulbar block and topical anesthesia. After pupillary constriction using pilocarpine and/or acetylcholine (Miochol®), a viscoelastic (Healon $5 \circledR$ ) was introduced through a paracentesis. A $6.0 \mathrm{~mm}$ (Artisan/Verisyse 6), 5.0 (Artisan/ Verisyse 5), or $3.2 \mathrm{~mm}$ (Artiflex) scleral incision was made 
Fig. 1 Scheimpflug imaging (Pentacam HR) of two different patients. a Sagittal curvature front of a classic keratoconus (patient A). b Sagittal curvature front of a PMD-like ectasia (patient B). c Posterior elevation map with a central maximal posterior elevation of the patient A. d Posterior elevation map with a slightly inferior maximal posterior elevation of the patient B. (PMD, pellucidal marginal degeneration)
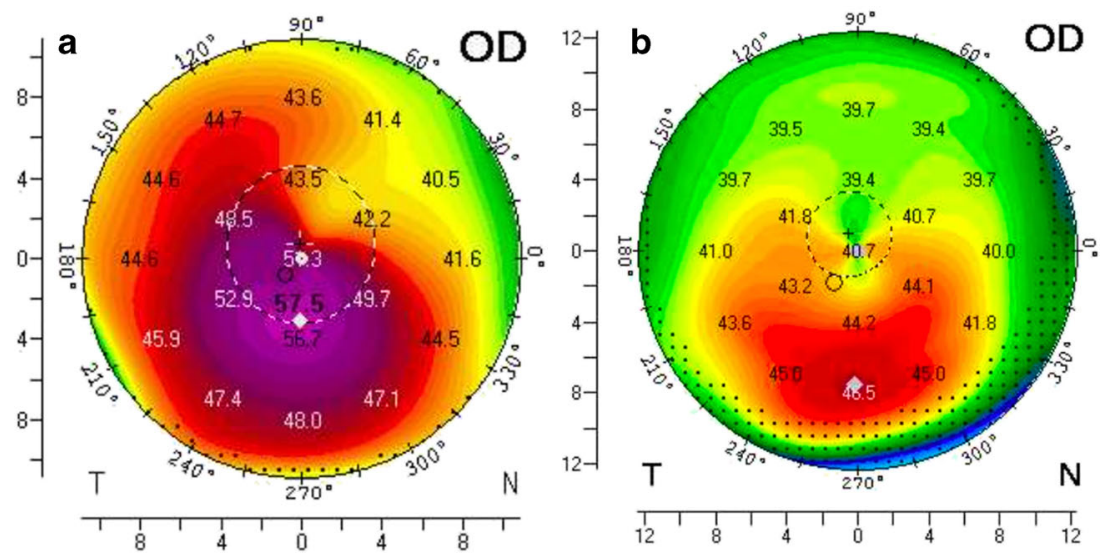

C

(B) Excl. $3.5 \mathrm{~mm} \quad \mathrm{i}=6.16$ Float, Dia $=8.00$

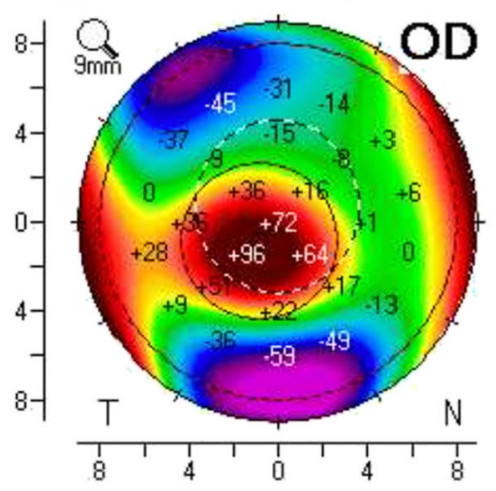

d

(B) Excl.3.0mm r $=6.65$ Float, Dia $=8.00$

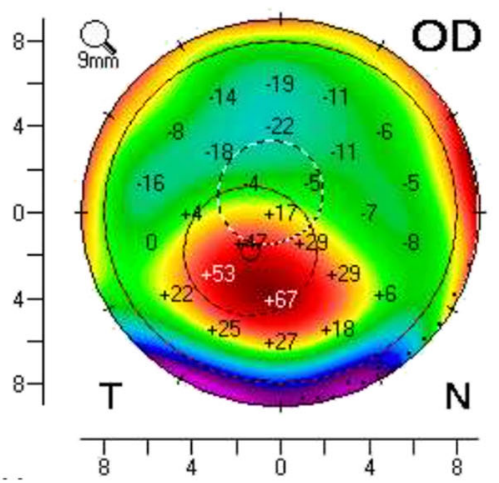

at 12 o'clock to implant a rigid or flexible pIOL respectively. The lens was rotated to the desired position, and the haptics were fixated to the iris by enclavation of the iris fibers into the claw opening while the lens was held in place at the optic edge using special Artisan/Artiflex holding forceps. Thereafter, an iridotomy was performed with a pair of scissors, the viscoelastic was completely removed, and the self-sealing tunnel incisions were secured with 10-0 sutures. Postoperatively, antibiotic and steroid eyedrops (Isoptomax $®)$ were applied five times per day for 2 weeks, afterward tapered off over 2 weeks.

\section{Numerical evaluation}

Descriptive analysis was performed for all variables in this study. Means and standard deviations of preoperative Scheimpflug imaging parameters (thinnest corneal thickness, $K_{\max }$, maximum posterior elevation (PE), eccentricity of PE, Qant, KI, and ISV) and demographic data as digital variables (age, eye) were documented or calculated. Multiple linear regression (backward elimination technique) was performed to detect any significant correlations between preoperative parameters and the outcome. All data were analyzed using Excel (2010, Microsoft Corp.) and SPSS (version 22.0, IBM Corp.). Statistical significance was assumed for $p<0.05$.

\section{Results}

Thirty-eight eyes of 22 patients ( $\mathrm{f}: \mathrm{m}=10: 12)$ were evaluated in this study. The average age was 33 years (range 20 to 47 years). Seventeen right and 21 left eyes were included.

The average Amsler-Krumeich staging was $1.76 \pm 0.69$ (range 1 to 3 ). Twenty-four eyes were diagnosed as keratoconus and 14 as PMD-like ectasia, none as classical PMD. Four patients did not show a distinct maximum posterior elevation in the inner $6.0 \mathrm{~mm}$ and therefore were not included in the evaluation of the posterior float. Table 1 shows the preoperative Scheimpflug parameters.

The postoperative uncorrected distance visual acuity (UDVA $_{\text {post }}$ ) is shown in Fig. 2a. The mean UDVA post was $0.25 \pm 0.15 \log$ MAR (mean decimal 0.58 ) and was not statistically different from mean corrected distance visual acuity $\left(\mathrm{CDVA}_{\text {pre }}\right)$ which was $0.24 \pm 0.13 \log \mathrm{MAR}$ (mean decimal $0.59)(p=0.688)$. Seventy-nine percent of all patients reached a UDVA of $0.3 \log$ MAR (decimal 0.5 ) and $13 \%$ of 0.1 logMAR (decimal 0.8) respectively.

The correlation of preoperative parameters with the $\mathrm{UDVA}_{\text {post }}$, the efficacy index (UDVA $\mathrm{U}_{\text {post }} / \mathrm{CDVA}_{\text {pre }}$ ), and the number of eyes reaching an efficacy index $\geq 1$ (UDVA $_{\text {post }} /$ $\mathrm{CDVA}_{\text {pre }} \geq 1$ ) is shown in Table 2. A higher AmslerKrumeich stage and preoperative MAE were correlated with 
Table 1 Data from preoperative Scheimpflug imaging (Pentacam HR) of 38 eyes

\begin{tabular}{lc}
\hline Parameters & preoperative values (mean \pm SD) \\
\hline$K_{\max }$ & $51.92 \pm 5.26$ \\
$K 1$ & $43.9 \pm 3.01$ \\
$K 2$ & $47.0 \pm 3.29$ \\
Astigmatism & $3.23 \pm 1.87$ \\
$R_{\min }$ & $6.61 \pm 0.66$ \\
KI & $1.20 \pm 0.14$ \\
CKI & $1.03 \pm 0.03$ \\
IVA & $22.31 \pm 0.54$ \\
ISV & $75.26 \pm 39.15$ \\
IHD & $0.0945 \pm 0.0655$ \\
IHA & $22.31 \pm 17.77$ \\
Posterior float & \\
$n$ & $34(90 \%)$ \\
Eccentricity of post float $(\mathrm{mm})$ & $1.23 \pm 0.56$ \\
Amplitude $(\mu \mathrm{m})$ & $61.27 \pm 28.4$ \\
Thinnest pachymetry $(\mu \mathrm{m})$ & $446.5 \pm 45.4$ \\
\hline
\end{tabular}

$S D$ standard deviation; $K_{\max }$ maximum anterior sagittal curvature; Rmin minimum radius of curvature; $K I$ keratoconus index; $C K I$ center keratoconus index; IVA index of surface asymmetry; ISV index of surface variance; $I H D$ index of height decentration; IHA index of height asymmetry

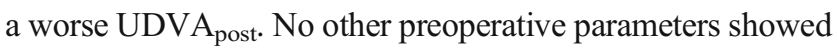
a significant influence on the UDVA post $_{\text {. }}$

The diagnosis PMD-like ectasia $(p=0.046)$ and a lower preoperative astigmatism $(p=0.019)$ in the manifest refraction were the only parameters significantly correlated with a higher efficacy index. A higher eccentricity of the maximum posterior elevation was a significant predictive factor for a higher number of eyes achieving an efficacy index $\geq 1(p=0.021)$. None of the other parameters showed a significant influence on the efficacy index.

Efficacy is shown in Fig. 2b. Fourteen patients (34\%) showed a better $\mathrm{UDVA}_{\text {post }}$ than $\mathrm{CDVA}_{\text {pre. }}$. Twenty-seven eyes $(71 \%)$ reached a $\mathrm{UDVA}_{\text {post }} / \mathrm{CDVA}_{\text {pre }} \geq 1$, all eyes $(100 \%)$ with the diagnosis PMD-like ectasia but only 13 eyes (54\%) with keratoconus reached a $\mathrm{UDVA}_{\text {post }} / \mathrm{CDVA}_{\text {pre }} \geq 1$, which illustrates a significant difference between the two groups $(p=0.003)$. The efficacy index of eyes with keratoconus versus PMD-like ectasias is shown in Fig. 2d.

The mean absolute spherical equivalent (MAE) was significantly reduced from $5.71 \pm 4.96 \mathrm{D}$ to $1.25 \pm 1.20 \mathrm{D}$ $(p<0.001)$. The spherical equivalent refractive accuracy is shown in Fig. 2e. Safety is shown in Fig. 2c. Only one eye lost one line. Endothelial cell count (ECC) was $2728 \pm 235$ cells $/ \mathrm{mm}^{2}$ pre- and $2778 \pm 142$ cells $/ \mathrm{mm}^{2}$ postoperatively $(p=0.548)$. ECC could only be measured in 24 eyes postoperatively due to loss of follow-up.

\section{Discussion}

The major findings of this study are the following:

- Phakic iris-fixated anterior chamber lenses offer a feasible refractive treatment for stabilized keratoconus.

- The UDVA after pIOL implantation is equal or better than the preoperative CDVA in $71 \%$ and better in $34 \%$ in eyes with keratoconus. None of the patients lost two lines.

- Advanced keratoconus and a high MAE are correlated with a worse postoperative UDVA.

- The implantation of pIOLs shows better refractive results in patients with PMD-like ectasia than in patients with classic keratoconus.

Ever since the progression of keratoconus can be stopped by CXL [8], there is an increasing, relatively young population with the desire to improve UDVA by refractive treatment. Glasses only allow limited visual acuity in these cases; and if the patient develops contact lens intolerance, there have been little options for visual rehabilitation until now. Topographyguided laser ablation combined with CXL had been performed in several cases [18-20]. However, corneal laser ablation increases the risk of progressive corneal ectasia in eyes with keratoconus, especially when higher corrections are needed and is therefore considered contraindicated or at least highly controversial $[9,10]$. Customized crosslinking shows promising results in terms of regularization of the cornea, but the technology cannot correct higher refractive errors [21].

Although the implantation of pIOLs was not recommended for keratectasias in the first place and the lens manufacturers proclaimed in their exclusion criteria that the lenses were meant for regular astigmatism only [11], favorable results in a few case studies have been achieved by implantation of pIOLs and ICLs in stable keratectasia in recent years [12. 13, 22]. Izquierdo et al. [12] reported the implantation of anterior chamber phakic Artiflex lenses in 11 eyes with grade I or II keratoconus 6 months after CXL. Only spherical Artiflex lenses were used, but postoperative UDVA of $0.3 \operatorname{logMAR}$ or better was observed in all patients. More recently, Güell and coworkers published a study including 17 eyes with progressive grade I or II keratoconus with regular central astigmatism receiving pIOL implantation 3 months after CXL [13]. The efficacy in terms of postoperative UDVA versus preoperative CDVA was comparable with our results. A total of 94.1\% reached a postoperative UDVA of $0.3 \log$ MAR or better, which was also the minimum reached CDVA preoperatively. Hashmani $S$ et al. reported a case of bilateral Artiflex implantation 4 months after CXL achieving bilateral postoperative UDVA of $0.3 \log$ MAR equivalent to preoperative CDVA [14]. Fadlallah A et al. reported significantly improved UDVA and SE after ICL implantation in 16 eyes 6 months after CXL [22].

To our knowledge, none of these or any other studies so far have evaluated the influence of preoperative factors on the 
Fig. 2 Standard graphs for reporting intraocular lens-based refractive surgery. a UDVA. b Difference between postoperative UDVA and preoperative CDVA. c Changes in CDVA. d Efficacy of patients with keratoconus versus PMD-like ectasia. e Accuracy of SE refraction (UDVA, uncorrected corrected distance visual acuity; CDVA, corrected distance visual acuity; PMD, pellucidal marginal degeneration; SE, spherical equivalent)
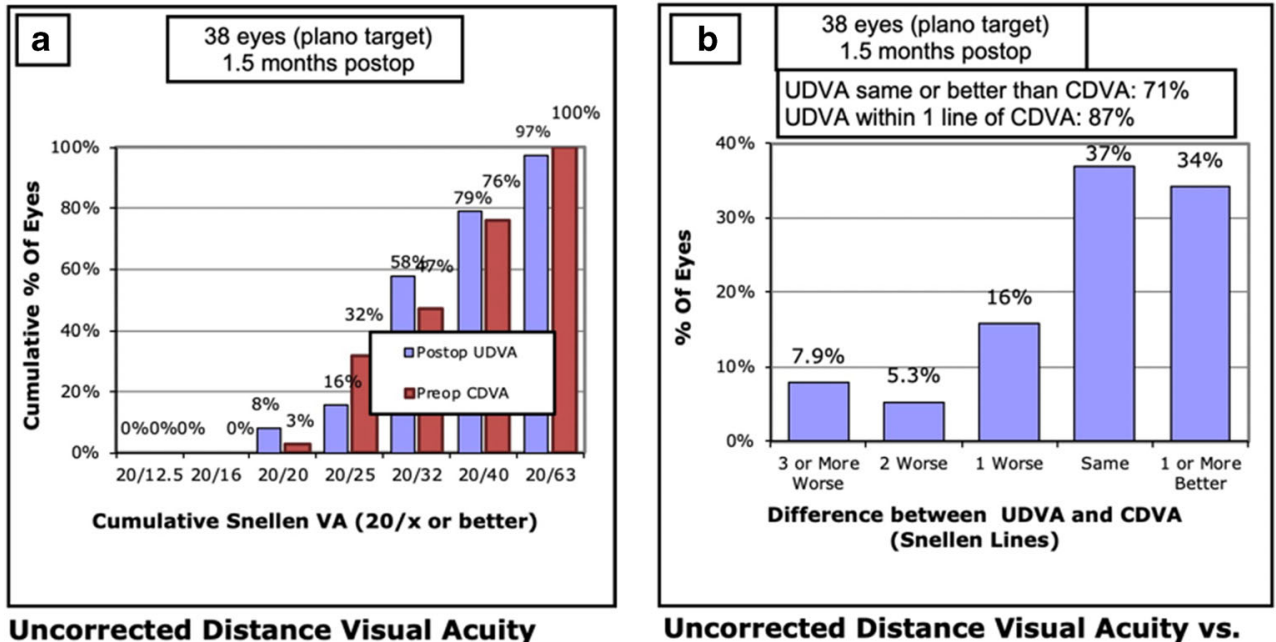

Uncorrected Distance Visual Acuity vs. Corrected Distance Visual Acuity

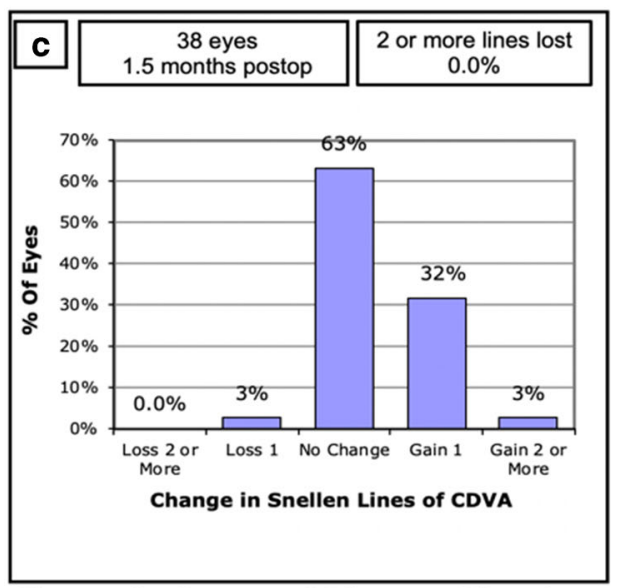

\section{Change in Corrected Distance Visual Acuity}

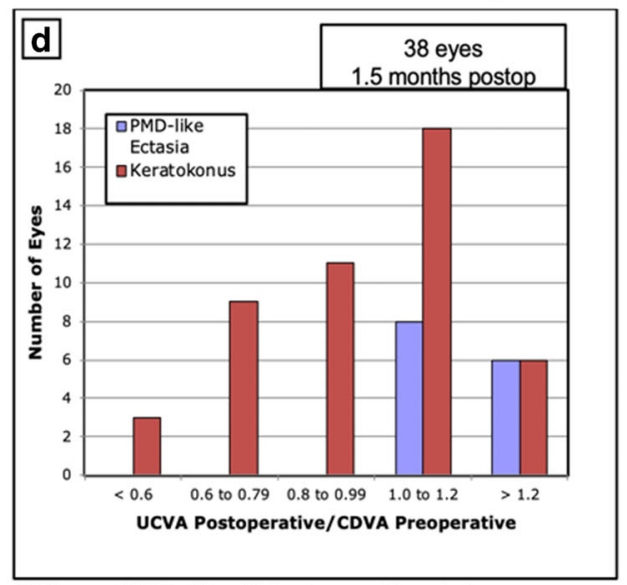

Efficacy PMD-like Ectasia vs. Keratokonus

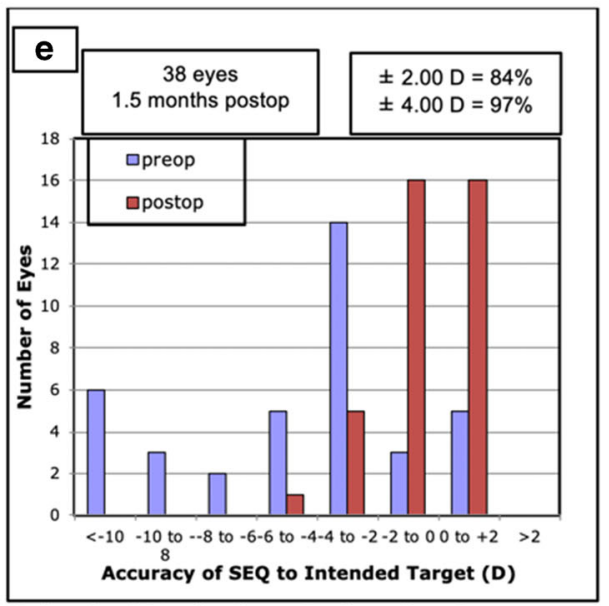

Spherical Equivalent Refractive Accuracy refractive outcome of the procedure. But hardly surprising, especially the phenotype of the keratectasia seems to have a relevant influence on the efficacy. Implantation of pIOLs in patients with PMD-like ectasia showed significantly better efficacy (UDVA $A_{\text {post }} / \mathrm{CDVA}_{\text {pre }}$ ) than in patients with classical keratoconus. This might be due to the higher degree of regular central astigmatism in patients with PMD or PMD-like ectasia, as pIOLs only allow for correcting regular astigmatism. Accordingly, spectacle correction works better in PMD than in keratoconus [23]. Therefore, the implantation of pIOLs can particularly be recommended in PMD-like ectasia and most probably PMD. Still, our results for keratoconus patients are pleasant 
Table 2 Correlation between preoperative parameters and outcome

\begin{tabular}{|c|c|c|c|}
\hline Parameters & UDVA $_{\text {post }}$ & $\begin{array}{l}\text { Efficacy index } \\
\left(\mathrm{UDVA}_{\text {post }} / \mathrm{CDVA}_{\text {pre }}\right)\end{array}$ & $\begin{array}{l}\text { Efficacy index } \geq 1 \\
\left(\mathrm{UDVA}_{\text {post }} / \mathrm{CDVA}_{\text {pre }} \geq 1\right)\end{array}$ \\
\hline Diagnosis & $\begin{array}{l}R=0.247 \\
p=0.135\end{array}$ & $\begin{array}{l}R=0.394 \\
p=0.046\end{array}$ & $p=0.003$ \\
\hline Amsler-Krumeich stage & $\begin{array}{l}R=-0.285 \\
p=0.014\end{array}$ & $\begin{array}{l}R=0.093 \\
p=0.580\end{array}$ & $p>0.05$ \\
\hline$K_{\max }$ & $\begin{array}{l}R=-0.229 \\
p=0.167\end{array}$ & $\begin{array}{l}R=0.037 \\
p=0.826\end{array}$ & $p>0.05$ \\
\hline Astigmatism (Scheimpflug) & $\begin{array}{l}R=-0.195 \\
p=0.240\end{array}$ & $\begin{array}{l}R=0.292 \\
p=0.075\end{array}$ & $p>0.05$ \\
\hline$R_{\min }$ & $\begin{array}{l}R=0.196 \\
p=0.227\end{array}$ & $\begin{array}{l}R=-0.122 \\
p=0.465\end{array}$ & $p>0.05$ \\
\hline KI & $\begin{array}{l}R=-0.248 \\
p=0.134\end{array}$ & $\begin{array}{l}R=0.218 \\
p=0.189\end{array}$ & $p=0.083$ \\
\hline CKI & $\begin{array}{l}R=-0.161 \\
p=0.334\end{array}$ & $\begin{array}{l}R=0.040 \\
p=0.810\end{array}$ & $p>0.05$ \\
\hline IVA & $\begin{array}{l}R=-0.242 \\
p=0.143\end{array}$ & $\begin{array}{l}R=0.250 \\
p=0.130\end{array}$ & $p=0.072$ \\
\hline ISV & $\begin{array}{l}R=-0.292 \\
p=0.075\end{array}$ & $\begin{array}{l}R=0.219 \\
p=0.187\end{array}$ & $p>0.05$ \\
\hline IHD & $\begin{array}{l}R=-0.324 \\
p>0.05\end{array}$ & $\begin{array}{l}R=0.162 \\
p=0.330\end{array}$ & $p>0.05$ \\
\hline IHA & $\begin{array}{l}R=-0.171 \\
p=0.305\end{array}$ & $\begin{array}{l}R=0.104 \\
p=0.534\end{array}$ & $p>0.05$ \\
\hline Posterior float & & & \\
\hline Eccentricity of posterior float & $\begin{array}{l}R=0.308 \\
p=0.076\end{array}$ & $\begin{array}{l}R=0.318 \\
p=0.067\end{array}$ & $p=0.021$ \\
\hline Amplitude & $\begin{array}{l}R=-0.107 \\
p=0.546\end{array}$ & $\begin{array}{l}R=0.255 \\
p=0.145\end{array}$ & $p>0.05$ \\
\hline Thinnest pachymetry & $\begin{array}{l}R=0.338 \\
p>0.05\end{array}$ & $\begin{array}{l}R=-0.078 \\
p=0.639\end{array}$ & $p>0.05$ \\
\hline MAE & $\begin{array}{l}R=-0.303 \\
p=0.006\end{array}$ & $\begin{array}{l}R=-0.187 \\
p=0.261\end{array}$ & $p>0.05$ \\
\hline Sphere (subjective refraction) & $\begin{array}{l}R=0.282 \\
p=0.86\end{array}$ & $\begin{array}{l}R=0.284 \\
p=0.084\end{array}$ & $p>0.05$ \\
\hline Astigmatism (subjective refraction) & $\begin{array}{l}R=0.033 \\
p=0.844\end{array}$ & $\begin{array}{l}R=-4.59 \\
p=0.019\end{array}$ & $p>0.05$ \\
\hline
\end{tabular}

$U D V A_{\text {post }}$ postoperative uncorrected distance visual acuity; $C D V A_{\text {pre }}$ preoperative corrected distance visual acuity; $R$ correlation coefficient; $K_{\max }$ maximum anterior sagittal curvature; $R_{\min }$ minimum radius of curvature; $K I$ keratoconus index; $C K I$ center keratoconus index; IVA index of surface asymmetry; ISV index of surface variance; $I H D$ index of height decentration; IHA index of height asymmetry; MAE mean absolute spherical equivalent and a success for patients as well. Our knowledge from this study is most likely valid for ICL implantation in keratectasia too and might support the preoperative planning of cataract surgery and ease the selection of (pseudophakic) toric IOLs.

The Amsler-Krumeich stage of the keratectasia did not have an impact on the efficacy of the intervention, but the postoperative UDVA was significantly worse in progressed keratectasia (higher Amsler-Krumeich stage) going along with high MAE. Worse results for patients with higher preoperative refractive error were found for pIOL implantation for myopia earlier [23].

Dick et al. reported UDVA after pIOL implantation for myopia in 290 eyes of $0.3 \log$ MAR or better in $97.2 \%$ [24]. A multicenter study with 662 eyes with moderate to high myopia enrolled found a postoperative UDVA of 0.3 $\log$ MAR in $84 \%$ which is only slightly better than our results (79\%) [25]. This comparison indicates that a reasonable UDVA can be reached quite reliably for patients suffering from mild to moderate corneal ectasia too.

The timing of the implantation of the pIOL should be discussed critically. Some authors suggested to wait 3 or
6 months after CXL before implanting the pIOL $[12,13]$. In our study, the average interval between the two procedures was 12 months. We believe a minimum interval of 6 months should be maintained to have a more stable preoperative refraction, as most flattening is observed rather early after CXL [26]. However, few cases with continuous flattening after CXL could suffer from later occurring refractive changes [27]. Such cases could not be detected in this study, as we monitored the early postoperative phase only.

The validity of this study might be affected by the high standard deviation of the Scheimpflug imaging in progressed keratectasia and the sample size which still to our knowledge is the biggest group published. Furthermore, long-term follow-up and longer intervals between CXL and pIOL implantation might be favorable in terms of ongoing flattening due to CXL. Additional surgical effort for future surgeries such as cataract surgery or keratoplasty where the pIOL has to be removed should be discussed with the patient and kept in mind by the surgeon. 
In conclusion, this study shows that the implantation of pIOLs is a valuable procedure for visual rehabilitation in eyes with keratectasia. Patients with more eccentric ectasia and decentered maximum posterior elevation as it is present in PDM-like ectasia seem to benefit the most from such a procedure.

Funding Open Access funding provided by Johannes Kepler University Linz.

\section{Compliance with ethical standards}

Ethical approval Ethical approval was waived by the local Ethics Committee (Berliner Ärztekammer, Eth-36/19) in view of the retrospective nature of the study and all the procedures being performed were part of the routine care.

Conflict of interest All authors certify that they have no affiliations with or involvement in any organization or entity with any financial interest (such as honoraria; educational grants; participation in speakers' bureaus; membership, employment, consultancies, stock ownership, or other equity interest; and expert testimony or patent-licensing arrangements), or non-financial interest (such as personal or professional relationships, affiliations, knowledge, or beliefs) in the subject matter or materials discussed in this manuscript.

None of the authors has financial interests.

Informed consent This type of study does not require informed consent.

Open Access This article is licensed under a Creative Commons Attribution 4.0 International License, which permits use, sharing, adaptation, distribution and reproduction in any medium or format, as long as you give appropriate credit to the original author(s) and the source, provide a link to the Creative Commons licence, and indicate if changes were made. The images or other third party material in this article are included in the article's Creative Commons licence, unless indicated otherwise in a credit line to the material. If material is not included in the article's Creative Commons licence and your intended use is not permitted by statutory regulation or exceeds the permitted use, you will need to obtain permission directly from the copyright holder. To view a copy of this licence, visit http://creativecommons.org/licenses/by/4.0/.

\section{References}

1. Pouliquen Y (1987) Keratoconus. Eye 1(1):1-14

2. Andreassen TT, Simonsen AH, Oxlund H (1980) Biomechanical properties of keratoconus and normal corneas. Exp Eye Res 31(4):435-441

3. Koc M, Tekin K, Inanc M, Kosekahya P, Yilmazbas P (2018) Crab claw pattern on corneal topography: pellucid marginal degeneration or inferior keratoconus? Eye 32(1):11-18

4. Karabatsas CH, Cook SD (1996) Topographic analysis in pellucid marginal corneal degeneration and keratoglobus. Eye 10(4):451-455

5. Fischinger I, Seiler TG, Santhirasegaram K, Pettenkofer M, Lohmann CP, Zapp D (2018) Corneal crosslinking (CXL) with $18-\mathrm{mW} / \mathrm{cm} 2$ irradiance and $5.4-\mathrm{J} / \mathrm{cm} 2$ radiant exposure - early postoperative safety. Graefes Arch Clin Exp Ophthalmol 256(8):1521-1525

6. Pircher N, Lammer J, Holzer S, Gschließer A, Schmidinger G (2019) Corneal crosslinking for pellucid marginal degeneration. J Cataract Refract Surg 45(8):1163-1167

7. Rabinowitz YS (1998) Keratoconus. Surv Ophthalmol 42(4):297-319
8. Spoerl E, Huhle M, Seiler T (1998) Induction of cross-links in corneal tissue. Exp Eye Res 66(1):97-103

9. Randleman JB, Woodward M, Lynn MJ, Stulting RD (2008) Risk assessment for ectasia after corneal refractive surgery. Ophthalmology 115(1):37-50.e4

10. Randleman JB, Trattler WB, Stulting RD (2008) Validation of the ectasia risk score system for preoperative laser in situ Keratomileusis screening. Am J Ophthalmol 145(5):813-818.e2

11. Lovisolo CF, Reinstein DZ (2005) Phakic intraocular lenses. Surv Ophthalmol 50(6):549-587

12. Izquierdo L, Henriquez MA, McCarthy M (2011) Artiflex phakic intraocular lens implantation after corneal collagen cross-linking in keratoconic eyes. J Refract Surg 27(7):482-487

13. Güell JL, Morral M, Malecaze F, Gris O, Elies D, Manero F (2012) Collagen crosslinking and toric iris-claw phakic intraocular lens for myopic astigmatism in progressive mild to moderate keratoconus. J Cataract Refract Surg 38(3):475-484

14. Hashmani S, Hashmani N, Memon RS (2017) Corneal collagen cross-linking combined with an artiflex iris-fixated anterior chamber phakic intraocular lens implantation in a patient with progressive Keratoconus. Case Rep Ophthalmol 8(3):482-488

15. Venter J (2009) Artisan phakic intraocular lens in patients with keratoconus. J Refract Surg 25(9):759-764

16. Kim JT, Zloty P (2012) Simplified nomenclature for describing keratoconus. Int J Keratoconus Ectatic Corneal Dis 1(1):31-35

17. Krumeich JH, Daniel J, Knülle A (1998) Live-epikeratophakia for keratoconus. J Cataract Refract Surg 24(4):456-463

18. Kanellopoulos AJ, Binder PS (2007) Collagen cross-linking (CCL) with sequential topography-guided PRK. Cornea 26(7):891-895

19. Krueger RR, Kanellopoulos AJ (2010) Stability of simultaneous topography-guided photorefractive keratectomy and riboflavin/ UVA cross-linking for progressive keratoconus: case reports. J Refract Surg 26(10):S827-S832

20. Kymionis GD, Kontadakis GA, Kounis GA, Portaliou DM, Karavitaki AE, Magarakis M, Yoo S, Pallikaris IG (2009) Simultaneous topography-guided PRK followed by corneal collagen cross-linking for keratoconus. J Refract Surg 25(9):S807-S811

21. Seiler TG, Fischinger I, Koller T, Zapp D, Frueh BE, Seiler T (2016) Customized corneal cross-linking: one-year results. Am J Ophthalmol 166:14-21

22. Fadlallah A, Dirani A, El Rami H, Cherfane G, Jarade E (2013) Safety and visual outcome of visian toric ICL implantation after corneal collagen cross-linking in keratoconus. J Refract Surg 29(2):84-89

23. Güell JL, Morral M, Gris O, Gaytan J, Sisquella M, Manero F (2008) Five-year follow-up of 399 phakic Artisan-Verisyse implantation for myopia, hyperopia, and/or astigmatism. Ophthalmology 115(6):1002-1012

24. Dick HB, Alió J, Bianchetti M, Budo C, Christiaans BJ, ElDanasoury MA et al (2003) Toric phakic intraocular lens: European multicenter study. Ophthalmology 110(1):150-162

25. Stulting RD, John ME, Maloney RK, Assil KK, Arrowsmith PN, Thompson VM, US Verisyse Study Group (2008) Three-year results of Artisan/Verisyse phakic intraocular lens implantation. Ophthalmology 115(3):464-472.e1

26. Raiskup-Wolf F, Hoyer A, Spoerl E, Pillunat LE (2008) Collagen crosslinking with riboflavin and ultraviolet-a light in keratoconus: long-term results. J Cataract Refract Surg 34(5):796-801

27. Noor IH, Seiler TG, Noor K, Seiler T (2018) Continued long-term flattening after corneal cross-linking for keratoconus. J Refract Surg 34(8):567-570

Publisher's note Springer Nature remains neutral with regard to jurisdictional claims in published maps and institutional affiliations. 